\title{
An introduction to the special issue "The contribution of pannexin-1, connexins and CALHM ATP-release channels to purinergic signalling"
}

\author{
Charles Kennedy ${ }^{1}$ \\ Published online: 13 November 2021 \\ (c) The Author(s), under exclusive licence to Springer Nature B.V. 2021
}

As the readership of this journal understands, extracellular nucleotides, such as ATP, act via P2X and P2Y receptors to elicit many physiological and pathophysiological actions and roles throughout the body. A variety of mechanisms have been discovered and characterised by which cells can release intracellular nucleotides. This special issue of Purinergic Signalling - "The contribution of pannexin-1, connexins and CALHM ATP-release channels to purinergic signalling”, assembled by myself and Nick Dale, focusses on large pore, transmembrane channels that are permeable to ATP and so enable it to act as an autocrine and paracrine signalling molecule.

The reviews in this issue cover a diverse range of tissues, cell types and pathologies, including epilepsy, sensory perception (nutritional sensing by tanycytes and pain), inflammation in the cardiovascular and musculoskeletal systems, cancer, obesity, ischaemia-reperfusion injury and HIV. The extent and depth of these conditions demonstrate the importance of these channels in purinergic signalling, but it is also clear that there is still much that remains to be discovered about how their expression and function are modulated and controlled and how they may be targeted for novel therapeutic approaches. We hope that these reviews will provide a useful overview of this area of research and perhaps help inspire new directions and avenues in your own research.

\author{
Dr. Charles Kennedy \\ c.kennedy@strath.ac.uk \\ Editor-in-Chief \\ Purinergic Signalling
}

\section{Declarations}

Conflicts of interest Charles Kennedy declares that he has no conflict of interest.

Nick Dale declares that he has no conflict of interest.

Ethical approval This article does not contain any studies with human participants or animals performed by any of the authors.

Publisher's note Springer Nature remains neutral with regard to jurisdictional claims in published maps and institutional affiliations.
Charles Kennedy

c.kennedy@strath.ac.uk

1 Strathclyde Institute of Pharmacy \& Biomedical Sciences, University of Strathclyde, John Arbuthnott Building, 161

Cathedral St, Glasgow G4 ORE, Scotland 